\title{
Microwave irradiation enhances the in vitro antifungal activity of citrus by- product aqueous extracts against Alternaria alternata
}

Konstantinos Papoutsis, Quan V. Vuong, Len Tesoriero, Penta Pristijono, Costas E. Stathopoulos, Stela Gkountina, Fiona Lidbetter, Michael C. Bowyer, Christopher J. Scarlett and John B. Golding

This is the peer reviewed version of the following article:

Papoutsis, K. et al. 2018. Microwave irradiation enhances the in vitro antifungal activity of citrus byproduct aqueous extracts against Alternaria alternata. International Journal of Food Science \& Technology.

which has been published in final form at doi: http://dx.doi.org/10.1111/ijfs.13732

This article may be used for non-commercial purposes in accordance with the Wiley Terms and Conditions for Self-Archiving 
Microwave irradiation enhances the in vitro antifungal activity of citrus by-product aqueous extracts against Alternaria alternata

Running title: Antifungal activity of citrus waste extracts

Konstantinos Papoutsis, ${ }^{1 *}$ Quan V. Vuong, ${ }^{1}$ Len Tesoriero, ${ }^{2}$ Penta Pristijono, ${ }^{1}$ Costas E. Stathopoulos, ${ }^{3}$ Stela Gkountina, ${ }^{2}$ Fiona Lidbetter, ${ }^{2}$ Michael C. Bowyer, ${ }^{1}$ Christopher J. Scarlett $^{1} \&$ John B. Golding ${ }^{1,2}$

${ }^{1}$ School of Environmental and Life Sciences, The University of Newcastle PO Box 127 Ourimbah, NSW 2258, Australia

${ }^{2}$ NSW Department of Primary Industries, Locked Bag 26 Gosford, NSW 2250, Australia

${ }^{3}$ Division of Food and Drink School of Science, Engineering and Technology University of Abertay Dundee DD1 1HG UK

*Corresponding author: School of Environmental and Life Sciences, The University of Newcastle PO Box 127 Ourimbah, NSW 2258, Australia; Email address: Konstantinos.Papoutsis@uon.edu.au. 


\section{Summary}

The effect of two lemon by-product aqueous extracts at different concentrations $(14,7$, 3.5 and $1 \mathrm{mg} \mathrm{mL}^{-1}$ ) were tested against the in vitro growth of Alternaria alternata. Prior to extraction one batch of by-product was dehydrated by freeze-drying (untreated byproduct), while the other batch was treated by microwave irradiation in conjunction with freeze-drying (microwave treated by-product). High-performance liquid chromatography (HPLC) was employed for the identification of individual phenolic compounds with potent antifungal activities. Both lemon by-product aqueous extracts inhibited the mycelial growth and suppressed the spore germination of the fungus in a concentrationdependent manner. In general, the extracts obtained from the microwave treated lemon by-product displayed enhanced antifungal activity than those obtained from the untreated one. Scanning electron microscopy (SEM) revealed that both lemon by-product extracts affected the hyphal morphology of the fungus. The antifungal activity of the extracts was attributed to their phenolic acid and ascorbic acid contents.

Keywords: Mycelial growth inhibition; conidia; lemon waste; antifungal activity; phenolic compounds; sweet cherry. 


\section{Introduction}

Alternaria alternata is a pathogen affecting both fruits and vegetables in the field and during storage (Feliziani et al., 2013, Pane et al., 2016). To date, this pathogen is mainly controlled by preharvest applications of synthetic fungicides (Feliziani et al., 2013). However, the efficiency of some fungicides has been decreased due to the development of resistant strains of this pathogen (Avenot et al., 2016). Moreover, pesticide residues might lead to environmental pollution and development of chronic diseases in humans (Kim et al., 2017). Therefore, sustainable solutions for the control of pathogens implicated in fruit and vegetable decays should be explored.

Plant extracts contain a plethora of secondary metabolites which may be involved in plant defense mechanism (Tao et al., 2014, Prakash et al., 2015, Yang et al., 2016, Pane et al., 2016). Among the different classes of secondary metabolites polyphenols have an important contribution to the antifungal activities of the plant extracts (Wang et al., 2017). Pane et al. (2016) reported that the foliar extracts of Capsicum annuum effectively controlled A. alternata growth on cherry tomatoes and this effect was attributed to the presence of polyphenols in the extracts.

A large amount of citrus by-products are annually generated by the juice industry and are a good source of polyphenols (Papoutsis et al., 2017, Sharma et al., 2017). Phenolic compounds of citrus peels include phenolic acids (Ma et al., 2008), and flavonoids which are usually found in conjugated forms (Bilbao et al., 2007). However, it is known that the free forms of phenolics are more active than the bound ones (Xu et al., 2007, Wang et al., 2017). Several studies have shown that the liberation of the bound polyphenols can be achieved by the application of heat or irradiation treatments on the dried materials (Hayat et al., 2010, Kim et al., 2008, Papoutsis et al., 2016a, Papoutsis et al., 2016d). 
The aims of this study were: 1) to determine the bioactive profile of the aqueous crude extracts obtained from microwave treated and non-microwave treated lemon by-products with known antifungal activity against $A$. alternata, 2) to assess if microwave treatment of the freeze-dried lemon by-product can enhance the antifungal activities of the aqueous extracts, and 3) to assess growth patterns and identify morphological changes in the fungus hyphae using scanning electron microscopy.

\section{Materials and methods}

\section{Materials}

Lemon waste including peel, membranes and seeds, was kindly provided by a commercial

juicing factory in Kulnura, NSW, Australia. After seed removal, the remaining peels and membranes with a moisture content of $85 \pm 1 \%$ (mean \pm standard deviation) were freezedried for $48 \mathrm{~h}$ as described by Papoutsis et al. (2017). The dried by-product was then ground using a commercial blender (Waring 2-speed blender, John Morris Scientific, Chatswood, Australia) and the powder passed through a $1.40 \mathrm{~mm}$ mesh sieve (EFL 2000; Endecotts Ltd., London, England) was used for the extraction. The dried lemon byproduct was kept at $-18^{\circ} \mathrm{C}$ for further analysis.

\section{Extract preparation}

\section{Microwave treatment of freeze-dried lemon by-product powder}

Freeze-dried lemon by-product was treated according to Papoutsis et al. (2016a). Briefly, $1.5 \mathrm{~g}$ of freeze-dried lemon by-product was treated with $360 \mathrm{~W}$ for $5 \mathrm{~min}$ in a household microwave oven (1,200 W, frequency 2,450 MHz; Sharp Carousel, Abeno-ku, Osaka, Japan). After microwave treatment, the treated by-product was stored at $-18{ }^{\circ} \mathrm{C}$, until use. 


\section{Preparation of crude extract}

Extraction was performed according to Papoutsis et al. (2016b) with some modifications. Briefly, $5 \mathrm{~g}$ of microwave treated or untreated freeze-dried lemon by-product powder was mixed with $100 \mathrm{~mL}$ of water and placed in a water bath (Labec Laboratory equipment Pty. Ltd., Marrickville, NSW, Australia) at $95^{\circ} \mathrm{C}$ for $15 \mathrm{~min}$. After extraction, the aqueous extracts were filtered using a Whatman no.1 filter paper to remove solid material. The filtrate was then transferred to a round bottom flask and concentrated under reduced pressure at $40{ }^{\circ} \mathrm{C}$, using a rotary evaporator (Buchi Rotavapor B-480, Buchi Australia, Noble Park, VIC, Australia) before being freeze-dried for $48 \mathrm{~h}$, in order to obtain the crude extract as a powder.

\section{Phytochemical analysis of the extracts}

\section{Total phenolic content (TPC)}

The TPC of the crude extracts was determined according to Papoutsis et al. (2016b). Briefly, $1 \mathrm{~mL}$ of crude extract was mixed with $5 \mathrm{~mL}$ of $10 \%$ (v/v) Folin-Ciocalteu reagent. After 3 minutes, $4 \mathrm{~mL}$ of $7.5 \%$ (w/v) $\mathrm{Na}_{2} \mathrm{CO}_{3}$ were added to the mixture and incubated in the dark at ambient temperature for $1 \mathrm{~h}$. The absorbance of the solution was measured at $760 \mathrm{~nm}$ using a spectrophotometer (Varian Australia Pty. Ltd., Vic., Melbourne, Australia). The results were expressed as $\mathrm{mg}$ of gallic acid equivalents per $\mathrm{g}$ of dried extract (mg GAE (g d.e. $\left.)^{-1}\right)$.

\section{Total flavonoid content (TF)}

The TF of the crude extracts was determined according to Papoutsis et al. (2016b). Briefly, $2 \mathrm{~mL}$ of $\mathrm{H}_{2} \mathrm{O}$ and $0.15 \mathrm{~mL}$ of $5 \%(\mathrm{w} / \mathrm{v}) \mathrm{NaNO}_{2}$ were mixed with $0.5 \mathrm{~mL}$ of sample and incubated at ambient temperature for $6 \mathrm{~min}$. Then, $0.15 \mathrm{~mL}$ of $10 \%(\mathrm{w} / \mathrm{v}) \mathrm{AlCl}_{3}$ was 
added and left at ambient temperature for $6 \mathrm{~min}$. Subsequently, $2 \mathrm{~mL}$ of $4 \%(\mathrm{w} / \mathrm{v}) \mathrm{NaOH}$ and $0.7 \mathrm{~mL}$ of $\mathrm{H}_{2} \mathrm{O}$ were added and the mixture was incubated at ambient temperature for further $15 \mathrm{~min}$. The absorbance was measured at $510 \mathrm{~nm}$ using a spectrophotometer (Varian Australia Pty. Ltd., Vic., Melbourne, Australia). The results were expressed as $\mathrm{mg}$ of catechin equivalents per $\mathrm{g}$ of dried extract $\left(\mathrm{mg} \mathrm{CE}(\mathrm{g} \text { d.e. })^{-1}\right)$.

\section{Ascorbic acid content}

Ascorbic acid content of the crude extracts was determined according to Papoutsis et al. (2016c). Briefly, $3 \mathrm{~mL}$ of reagent solution $\left(0.6 \mathrm{M} \mathrm{H}_{2} \mathrm{SO}_{4}, 28 \mathrm{mM} \mathrm{Na}_{3} \mathrm{PO}_{4}\right.$ and $4 \mathrm{mM}$ ammonium molybdate) were mixed with $0.3 \mathrm{~mL}$ of diluted sample and incubated at 95 ${ }^{\circ} \mathrm{C}$ for $90 \mathrm{~min}$. After incubation, the absorbance was measured at $695 \mathrm{~nm}$ using a spectrophotometer (Varian Australia Pty. Ltd., Vic., Melbourne, Australia). Ascorbic acid was used as standard and the results were expressed as mg of ascorbic acid equivalents per $g$ of dried extract (mg AAE (g d.e. $\left.)^{-1}\right)$.

\section{Cupric Reducing Antioxidant Capacity (CUPRAC)}

CUPRAC was determined according to Papoutsis et al. (2016b). Briefly, $1 \mathrm{~mL}$ of $\mathrm{CuCl}_{2}$ $(10 \mathrm{mM})$ was mixed with $1 \mathrm{~mL}$ of neocuproine $(7.5 \mathrm{mM})$ and $1 \mathrm{~mL}$ of $\mathrm{NH}_{4} \mathrm{Ac}(\mathrm{pH} 7.0)$. Subsequently, $1.1 \mathrm{~mL}$ of sample was added to this mixture. The mixture was incubated at ambient temperature for $1.5 \mathrm{~h}$. The absorbance was measured at $450 \mathrm{~nm}$ using a spectrophotometer (Varian Australia Pty. Ltd., Vic., Melbourne, Australia). The results were expressed as mg of Trolox equivalents per $\mathrm{g}$ of dried extract (mg TE $\left.(\mathrm{g} \text { d.e. })^{-1}\right)$. 


\section{High-Performance Liquid Chromatography (HPLC)}

High-performance liquid chromatography (HPLC) (Shimadzu LC-20AD, Rydalmere, NSW, Australia) was employed for the identification of individual phenolic compounds of lemon by-product crude extracts. The standards and samples were filtered through a $0.45 \mu \mathrm{m}$ nylon filter, and $30 \mu \mathrm{L}$ was individually injected into a $\mathrm{C}_{18}$ reversed-phase column (Gemini 110A 5 m, $150 \times 4.6$ mm Phenomenex Australia Pty., Ltd., Lane Cove, NSW, Australia) supplied with a guard column (Gemini $\mathrm{C}_{18}, 4 \times 3.0 \mathrm{~mm}$ ). The column temperature was maintained at $30{ }^{\circ} \mathrm{C}$ (Phenomenex Therma Sphere TS-130 Column Heater, Phenomenex Australia Pty., Ltd., Lane Cove, NSW, Australia). UV detector was used for the identification of phenolic compounds. The mobile phase contained water: acetonitrile: formic acid, 95:4:1 (v:v:v) (Mobile Phase A) and acetonitrile (Mobile Phase B). The flow rate of the solvents was $1 \mathrm{~mL}$ per min, and the following gradient solution was used: $0 \min 5 \% \mathrm{~B} ; 15 \min , 20 \% \mathrm{~B} ; 35 \mathrm{~min}, 100 \% \mathrm{~B} ; 40 \mathrm{~min}, 5 \% \mathrm{~B} ; 50 \mathrm{~min}, 5 \% \mathrm{~B}$. The analysis was stopped after $60 \mathrm{~min}$. The system was equilibrated between runs for 10 min using $50 \%$ of mobile phase B. The identification of individual phenolic compounds was performed at $280 \mathrm{~nm}$ by comparing the retention times of the peaks obtained from the extracts to those obtained from the standard compounds. The quantification of the identified phenolic compounds was performed by an external standard method using standard curves and the results were expressed as $\mathrm{mg} \mathrm{g}^{-1}$. The standard curve for each phenolic compound (hesperidin, neohesperidin, rutin, $p$-coumaric acid, caffeic acid and sinapic acid) was linear $\left(R^{2}=0.9997,0.9999,0.9994,0.9986,0.9947\right.$ and 0.9988, respectively) in the range of $6.25-200 \mu \mathrm{g} \mathrm{mL}^{-1}$ methanol.

\section{In vitro antifungal activity determination against Alternaria alternata \\ Per cent growth inhibition}


The effects of two lemon by-product extracts at different concentrations $(14,7,3.5$, and $1 \mathrm{mg} \mathrm{mL} \mathrm{m}^{-1}$ ) on the mycelial growth of A. alternata (DAR No. 83294) isolated from infected sweet cherries (Prunus avium), were determined according to Tao et al. (2014) with some modifications. Briefly, $40 \mathrm{ml}$ of sterilized 1/4PDA medium was mixed with the appropriate amount of lemon by-product crude extract and then poured into petri dishes $(9 \mathrm{~cm})$. Unamended media were used as a negative control, while fludioxonil fungicide $\left(\right.$ Scholar $\left.^{\circledR}\right)$ at a concentration of $2.6 \mu \mathrm{L}$ per $\mathrm{mL}$ was used as a positive control. For exploring potential compounds with antifungal activity, standard compounds (hesperidin, rutin, $p$-coumaric acid and ascorbic acid) which have been identified in lemon by-product aqueous extracts were incorporated into the $1 / 4 \mathrm{PDA}$ in a concentration of $5 \mathrm{mM}$ (Ortuño et al., 2006). Petri dishes were inoculated with a 6-day-old A. alternata $(0.40 \mathrm{~cm})$, with the mycelial surface facing up and incubated at $25{ }^{\circ} \mathrm{C}$ for 7 days. Each experiment was conducted three times and each treatment had three replicates. The diameter growth was measured by a ruler and calculated by Equation 1, while the per cent growth inhibition rate to be calculated using Equation 2 (Tao et al., 2014).

$$
\text { Diameter growth }=X d-X i \text { (Eq. 1) }
$$

Where $\mathrm{Xd}$ is the growth in $\mathrm{cm}$ after 7 days and $\mathrm{Xi}$ is $0.40 \mathrm{~cm}$.

Per cent growth inhibition rate $=\left[\frac{D c-D t}{D c}\right] * 100 \% \quad$ (Eq. 2$)$

Where $\mathrm{Dc}=($ Diameter of control after 7 days $(\mathrm{cm})-$ initial diameter $(0.40)$ in $\mathrm{cm})$ and $\mathrm{Dt}=($ Diameter of treatments after 7 days $(\mathrm{cm})-$ initial diameter $(0.40)$ in $\mathrm{cm})$.

\section{Spore germination}

The spore germination was determined according to Yang et al. (2016) with some modifications. Standard compounds ( $p$-coumaric acid and ascorbic acid) at a concentration of $5 \mathrm{mM}$ and crude extracts of untreated and microwave treated lemon by- 
product at a concentration of 14 and $7 \mathrm{mg} \mathrm{ml}^{-1}$ were incorporated into the media ( $\left.1 / 4 \mathrm{PDA}\right)$ and poured onto a $7.5 \mathrm{~cm}$ sterile glass slide. Unamended media were used as a control. After solidifying, each slide was inoculated with $20 \mu \mathrm{L}$ of fungal spore suspension $(5 \times$ $10^{5}$ cells per $\mathrm{mL}$ ) and placed on a $9 \mathrm{~cm}$ Petri dish with wet filter paper at the bottom. After $6 \mathrm{~h}$ incubation at $25^{\circ} \mathrm{C}, 60$ spores per slide were examined using a microscope (Olympus $\mathrm{Bx} 41)$ and the number of germinated spores with germ tubes longer than twice the diameter of corresponding spores was counted. Each experiment was conducted three times and each treatment had three replicates.

\section{Scanning electron microscopy (SEM)}

A six-day-old fungus was subcultured onto 1/4PDA dishes contained the extract derived either from the treated or untreated lemon by-product at a concentration of $14 \mathrm{mg} \mathrm{ml}^{-1}$. Unamended media were used as a control. After incubation at $25^{\circ} \mathrm{C}$ for 3 days, segments $(5 \times 10 \mathrm{~mm})$ were cut at the periphery of the colony and were promptly placed in vials containing $2.5 \%$ glutaraldehyde in $0.05 \mathrm{M}$ phosphate buffer saline. The samples were kept in the solution for $48 \mathrm{~h}$ and then they were washed with distilled water 3 times for $10 \mathrm{~min}$ each time. Subsequently, the samples were dehydrated in ethanol series $(30 \%, 50 \%, 70 \%$, and $95 \%$ ) for $20 \mathrm{~min}$ in each ethanol dilution and finally in absolute ethanol for $30 \mathrm{~min}$. The samples were frozen using liquid nitrogen and freeze-dried. The dried samples were coated with gold (80 sec, $15 \mathrm{~mA}$ ) and were observed using ZEISS SIGMA VP scanning electron microscope (SEM).

\section{Statistical analysis}

All the data have been expressed as mean \pm standard deviation. All the phytochemical assays were conducted in triplicate, with an exception of the determination of individual 
phenolic compounds, where five replications were used. The means of all phytochemical assays were compared using the $t$-test at $P<0.05$. The effects of each treatment on per cent growth inhibition rate, diameter growth, and spore germination were assessed by Duncan's post hoc multiple comparison test with the SPSS statistical software (version 23, IBM, Crop., NY, USA) at $P<0.05$.

\section{Results and discussion}

\section{Polyphenol content and antioxidant capacity of lemon by-product aqueous extracts}

The TPC, TF, and cupric reducing antioxidant capacity of the extracts obtained from the microwave treated by-product were 53,13 , and $49 \%$, respectively, higher than those obtained from the untreated one $(P<0.05)$ (Table 1). Moreover, the aqueous extracts of the microwave treated lemon by-product had higher ascorbic acid content $(202.93 \pm 14.64$ $\left.\operatorname{mg} \operatorname{AAE}(\mathrm{g} \mathrm{d.e.})^{-1}\right)$ than those obtained from the untreated ones $(112.93 \pm 19.23 \mathrm{mg}$ AAE $\left.(\mathrm{g} \text { d.e. })^{-1}\right)$, indicating that microwave treatment of the freeze-dried lemon by-product enhances the recovery of ascorbic acid. This is in agreement with previous findings reporting higher retention of ascorbic acid in vegetables treated by heat (Cross \& Fung, 1982). Moreover, previous studies have mentioned that the polyphenol content and antioxidant capacity of citrus extracts can be enhanced by the application of microwave irradiation to the dried material (Hayat et al., 2010, Papoutsis et al., 2016a). Three phenolic acids (caffeic acid, $p$-coumaric acid, and sinapic acid) and three flavonoids (neohesperidin, hesperidin, and rutin) were identified and quantified by HPLC in both treated and untreated lemon by-products. The contents of all individual phenolic compounds were significantly higher in the extracts obtained after lemon by-product microwave treatment compared to those obtained from the untreated by-products $(P<0.05)$ (Table 2$)$. The higher caffeic acid, $p$-coumaric acid, sinapic acid, neohesperidin, 
hesperidin, and rutin yields obtained from the microwave treated by-product could be attributed to the liberation of the bound phenolics due to the heating effect during microwave treatment (Hayat et al., 2010).

\section{Effect of lemon by-product aqueous crude extracts on $A$. alternata mycelial growth} The effect of two lemon by-product extracts at different concentrations $(14,7,3.5$ and 1 $\mathrm{mg} \mathrm{mL} \mathrm{m}^{-1}$ ) on A. alternata mycelial growth can be seen in Fig. 1. Both extracts inhibited the mycelial growth of $A$. alternata in a concentration-dependent manner. The diameter growth of the fungus significantly decreased as the concentration of both extracts increased from 1 to $14 \mathrm{mg} \mathrm{mL}^{-1}$ (Fig. 1a), with the extracts obtained from the microwave treated lemon by-product showing higher per cent growth inhibition rate (ranging from 31 to $73 \%$ ) than those obtained from the untreated lemon by-product (ranging from 30 to $68 \%)(P<0.05)$ (Fig. 1b). The diameter growth of A. alternata in the negative control (unamended) was $6.85 \mathrm{~cm}$ after 7 days storage at $25^{\circ} \mathrm{C}$, while the fludioxonil fungicide (positive control) totally inhibited the growth of the fungus. Both extracts at the concentrations of 14 and $7 \mathrm{mg} \mathrm{mL}^{-1}$ significantly altered the morphology of A. alternata (Fig. S1). For exploring potential compounds with antifungal activity in the extracts, the effects of four standard compounds ( $p$-coumaric acid, ascorbic acid, rutin hesperidin) which have been identified in lemon by-product extracts were investigated in a concentration of $5 \mathrm{mM}$ (Fig. 1). Both ascorbic acid and $p$-coumaric acid exhibited strong antifungal activity against $A$. alternata, while the two flavonoids (rutin and hesperidin) had negligible effects on the growth of the fungus (Fig. S1). These results are in accordance with previous studies which found that phenolic acids inhibited the growth of A. alternata infected tomatoes and sweet cherries (Pane et al., 2016, Wang et al., 2017). Indeed the mechanisms of action of the bioactive compounds of plants are not completely 
understood (da Cruz Cabral et al., 2013). However, the antifungal activity of the lemon by-product aqueous extracts could be attributed to the presence of compounds contained hydroxyl $(\mathrm{OH})$ groups in their molecules, such phenolic acids and ascorbic acid, since hydroxyl $(\mathrm{OH})$ groups are able to form hydrogen bonds which modify a variety of intracellular factions in the fungi (da Cruz Cabral et al., 2013, Yang et al., 2016). This is further supported by the enhanced antifungal activity of the extracts obtained from the microwave lemon by-products which contained higher phenolic acid and ascorbic acid contents than those obtained from the untreated ones. The negligible antifungal activity of hesperidin and rutin implies that the position of the hydroxyl $(\mathrm{OH})$ group in the aromatic ring of the compounds may affect their antifungal activities. Future studies investigating synergistic and antagonistic interactions of phenolics and other bioactive compounds on the inhibition of A. alternata growth are encouraged.

\section{Morphological changes detected by using scanning electron microscopy (SEM)}

The hyphae of $A$. alternata grown on amended 1/4 PDA petri dishes (control) was regular, with a smooth surface and linearly shaped (Fig. 2a). In contrast, both extracts at the concentration of $14 \mathrm{mg} \mathrm{mL}^{-1}$ altered the morphology of the fungus hyphae, resulting in rough surfaces, cell wall collapse and loss of linearity (Fig. 2b, and c). Additionally, the formation of a layer of extruded material that covered the mycelia was observed in the hyphae treated with both lemon by-product aqueous extracts. The extracts obtained from the microwave treated lemon by-products resulted in greater hyphae damage (Fig. 2c) compared to those obtained from the untreated one (Fig. 2b). Similar results have been observed in A. alternata treated with essential oils (Castro et al., 2017), and in P. italicum treated with poplar buds extracts (Yang et al., 2016). In this study the morphology changes observed could be due to the interaction of some bioactive compounds contained 
in the lemon by-product extracts, such as phenolic acids or ascorbic acid, with membrane enzymes, leading to the loss of integrity of the hyphae cell walls (da Cruz Cabral et al., 2013). It has been reported that phenolic compounds may alter fungus cell permeability, leading to macromolecule leakage (da Cruz Cabral et al., 2013). This effect may explain the formation of a layer of extruded material that covered the mycelia of the A. alternata hyphae treated with the lemon by-product aqueous extracts (Fig. 2b, and c).

\section{Effect of microwave treated and untreated lemon by-product crude extracts on $A$.}

\section{alternata spore germination}

In the spore germination experiment, the extract concentrations of 14 and $7 \mathrm{mg} \mathrm{mL}^{-1}$ were selected since at these concentrations high per cent growth inhibition was achieved. The effect of two lemon by-product aqueous extracts at different concentrations on $A$. alternata spore germination can be seen in Fig. 3. The spore germination was lower in the media incorporated with the extracts obtained from the microwave treated lemon byproduct than those obtained from the untreated one $(P<0.05)$. The effects of ascorbic acid and $p$-coumaric acid on A. alternata spore germination were also investigated since these extracts showed strong per cent growth inhibition activity. Both ascorbic acid and $p$ coumaric acid inhibited the spore germination of the fungus (Fig. 3). These results are in accordance with Karim et al. (2016) who indicated that the methanol extracts of different Cistus L. species inhibited the spore germination of Geotrichum citri-aurantii and Yang et al. (2016) who showed that the extracts of poplar buds inhibited the germination of Penicillium italicum. Given that spore germination is a process that requires metabolic energy it could be hypothesized that bioactive compounds contained in lemon by-product aqueous extracts may affect the activity of enzymes implicated in the metabolic respiration of the fungus. 
The results of this study indicate that the aqueous extracts of lemon by-products contain bioactive compounds which could be potentially useful as an alternative to synthetic fungicides for controlling A. alternata. A large-scale application of plant extracts could be achieved by their incorporation into edible films (Guerreiro et al., 2016). However, the antifungal activities of the extracts might be affected by the composition of the film, as well as the methods and conditions being applied for film drying (Mayachiew et al., 2010). Therefore, future studies should be conducted investigating the incorporation of lemon by-product extracts into edible films and coatings, as well as to characterize their stability.

\section{Conclusions}

To sum up, lemon by-product aqueous extracts inhibited the growth and suppressed the spore germination of Alternaria alternata in a concentration-dependent manner. The in vitro antifungal and antioxidant activities of lemon by-product aqueous extracts can be enhanced by treating the dried lemon by-product with microwave energy. The antifungal effects of lemon by-product extracts were attributed to the presence of phenolic acids and ascorbic acid into the aqueous extracts. Lemon by-product extracts significantly changed the morphology of fungus hyphae, leading to a cell wall collapse and loss of linearity. Lemon by-product extracts could be potentially useful as an alternative to synthetic fungicides for controlling A. alternata. Future studies should investigate the incorporation of lemon by-product extracts into edible films and coatings, as well as to characterize their stability.

\section{Acknowledgements}


This research was supported by the University of Newcastle and Australian Research

Council (ARC) Training Centre for Food and Beverage Supply Chain Optimisation

(IC140100032). It was also supported by the Australian Citrus Postharvest Science

Program (Horticulture Innovation. CT 15010). The authors would like to thank Dr. Yun

Lin for supporting with the SEM analysis. We also thank Mick Lentini at Eastcoast Food and Beverages for the supply of the lemon by-product.

\section{References}

Avenot, H.F., Solorio, C., Morgan, D.P. \& Michailides, T.J. (2016). Sensitivity and crossresistance patterns to demethylation-inhibiting fungicides in California populations of Alternaria alternata pathogenic on pistachio. Crop Protection, 88, $72-78$.

Bilbao, M.L.M., Andrés-Lacueva, C., Jáuregui, O. \& Lamuela-Raventós, R.M. (2007). Determination of flavonoids in a Citrus fruit extract by LC-DAD and LC-MS. Food Chemistry, 101, 1742-1747.

Castro, J.C., Endo, E.H., De Souza, M.R., Zanqueta, E.B., Polonio, J.C., Pamphile, J.A., Ueda-Nakamura, T., Nakamura, C.V., Dias Filho, B.P. \& Abreu Filho, B.A.D. (2017). Bioactivity of essential oils in the control of Alternaria alternata in dragon fruit (Hylocereus undatus Haw.). Industrial Crops and Products, 97, 101-109.

Cross, G.A. \& Fung, D.Y. (1982). The effect of microwaves on nutrient value of foods. Critical Reviews in Food Science and Nutrition, 16, 355-381.

da Cruz Cabral, L., Fernández Pinto, V. \& Patriarca, A. (2013). Application of plant derived compounds to control fungal spoilage and mycotoxin production in foods. International Journal of Food Microbiology, 166, 1-14.

Feliziani, E., Santini, M., Landi, L. \& Romanazzi, G. (2013). Pre- and postharvest treatment with alternatives to synthetic fungicides to control postharvest decay of sweet cherry. Postharvest Biology and Technology, 78, 133-138.

Guerreiro, A.C., Gago, C.M.L., Faleiro, M.L., Miguel, M.G.C. \& Antunes, M.D.C. (2016). Edible coatings enriched with essential oils for extending the shelf-life of 'Bravo de Esmolfe' fresh-cut apples. International Journal of Food Science \& Technology, 51, 87-95.

Hayat, K., Zhang, X., Chen, H., Xia, S., Jia, C. \& Zhong, F. (2010). Liberation and separation of phenolic compounds from citrus mandarin peels by microwave heating and its effect on antioxidant activity. Separation and Purification Technology, 73, 371-376.

Karim, H., Boubaker, H., Askarne, L., Talibi, I., Msanda, F., Boudyach, E.H., Saadi, B. \& Ait Ben Aoumar, A. (2016). Antifungal properties of organic extracts of eight Cistus L. species against postharvest citrus sour rot. Letters in Applied Microbiology, 62, 16-22.

Kim, J.W., Lee, B.C., Lee, J.H., Nam, K.C. \& Lee, S.C. (2008). Effect of electron-beam irradiation on the antioxidant activity of extracts from Citrus unshiu pomaces. Radiation Physics and Chemistry, 77, 87-91. 
Kim, K.H., Kabir, E. \& Jahan, S.A. (2017). Exposure to pesticides and the associated human health effects. Science of The Total Environment, 575, 525-535.

Ma, Y.Q., Ye, X.Q., Fang, Z.X., Chen, J.C., Xu, G.H. \& Liu, D.H. (2008). Phenolic compounds and antioxidant activity of extracts from ultrasonic treatment of satsuma mandarin (Citrus unshiu Marc.) peels. Journal of Agricultural and Food Chemistry, 56, 5682-5690.

Mayachiew, P., Devahastin, S., Mackey, B.M. \& Niranjan, K. (2010). Effects of drying methods and conditions on antimicrobial activity of edible chitosan films enriched with galangal extract. Food Research International, 43, 125-132.

Ortuño, A., Báidez, A., Gómez, P., Arcas, M.C., Porras, I., García-Lidón, A. \& Río, J.A.D. (2006). Citrus paradisi and Citrus sinensis flavonoids: Their influence in the defence mechanism against Penicillium digitatum. Food Chemistry, 98, 351358.

Pane, C., Fratianni, F., Parisi, M., Nazzaro, F. \& Zaccardelli, M. (2016). Control of Alternaria post-harvest infections on cherry tomato fruits by wild pepper phenolic-rich extracts. Crop Protection, 84, 81-87.

Papoutsis, K., Pristijono, P., Golding, J. B., Stathopoulos, C. E., Bowyer, M. C., Scarlett, C. J. \& Vuong, Q. V. (2016a). Enhancement of the total phenolic compounds and antioxidant activity of aqueous Citrus limon L. pomace extract using microwave pretreatment on the dry powder. Journal of Food Processing and Preservation, DOI 10.1111/jfpp.13152.

Papoutsis, K., Pristijono, P., Golding, J. B., Stathopoulos, C. E., Bowyer, M. C., Scarlett, C. J. \& Vuong, Q. V. (2016b). Optimisation of aqueous extraction conditions for the recovery of phenolic compounds and antioxidants from lemon pomace. International Journal of Food Science and Technology, 51, 2009-2018.

Papoutsis, K., Pristijono, P., Golding, J.B., Stathopoulos, C.E., Bowyer, M.C., Scarlett, C.J. \& Vuong, Q.V. (2017). Effect of vacuum-drying, hot air-drying and freezedrying on polyphenols and antioxidant capacity of lemon (Citrus limon) pomace aqueous extracts. International Journal of Food Science \& Technology, 52, 880887.

Papoutsis, K., Pristijono, P., Golding, J. B., Stathopoulos, C.E., Scarlett, C.J., Bowyer, M.C. \& Vuong, Q.V. (2016c). Impact of different solvents on the recovery of bioactive compounds and antioxidant properties from lemon (Citrus limon L.) pomace waste. Food Science and Biotechnology, 25, 971-977.

Papoutsis, K., Vuong, Q.V., Pristijono, P., Golding, J.B., Bowyer, M.C., Scarlett, C.J. \& Stathopoulos, C.E. (2016d). Enhancing the total phenolic content and antioxidants of lemon pomace aqueous extracts by applying UV-C irradiation to the dried powder. Foods, 5, 55.

Prakash, B., Kedia, A., Mishra, P.K., Dwivedy, A.K. \& Dubey, N.K. (2015). Assessment of chemically characterised Rosmarinus officinalis L. essential oil and its major compounds as plant-based preservative in food system based on their efficacy against food-borne moulds and aflatoxin secretion and as antioxidant. International Journal of Food Science \& Technology, 50, 1792-1798.

Sharma, K., Mahato, N., Cho, M.H. \& Lee, Y.R. (2017). Converting citrus wastes into value-added products: Economic and environmently friendly approaches. Nutrition, 34, 29-46.

Tao, N., Jia, L. \& Zhou, H. (2014). Anti-fungal activity of Citrus reticulata Blanco essential oil against Penicillium italicum and Penicillium digitatum. Food Chemistry, 153, 265-271. 
Wang, M., Jiang, N., Wang, Y., Jiang, D. \& Feng, X. (2017). Characterization of Phenolic Compounds from Early and Late Ripening Sweet Cherries and Their Antioxidant and Antifungal Activities. Journal of Agricultural and Food Chemistry, 65, 54135420.

Xu, G., Ye, X., Chen, J. \& Liu, D. (2007). Effect of heat treatment on the phenolic compounds and antioxidant capacity of citrus peel extract. Journal of Agricultural and Food Chemistry, 55, 330-335.

Yang, S., Liu, L., Li, D., Xia, H., Su, X., Peng, L. \& Pan, S. (2016). Use of active extracts of poplar buds against Penicillium italicum and possible modes of action. Food Chemistry, 196, 610-618. 


\section{Tables}

Table 1. Total phenolic content (TPC), total flavonoid content (TF), ascorbic acid content, and antioxidant capacity (CUPRAC) of treated and untreated lemon by-products. Results are expressed as mean \pm standard deviation $(n=3)$.

\begin{tabular}{rcc}
\hline & Untreated by-product & Treated by-product \\
\hline TPC (mg GAE (g d.e. $\left.)^{-1}\right)$ & $40.94 \pm 1.40^{\mathrm{b}^{*}}$ & $62.82 \pm 1.58^{\mathrm{a}}$ \\
TF (mg CE $\left.(\mathrm{g} \text { d.e. })^{-1}\right)$ & $10.63 \pm 0.31^{\mathrm{b}}$ & $12.00 \pm 0.14^{\mathrm{a}}$ \\
Ascorbic acid (mg AAE $\left.(\mathrm{g} \text { d.e. })^{-1}\right)$ & $112.93 \pm 19.23^{\mathrm{b}}$ & $202.93 \pm 14.64^{\mathrm{a}}$ \\
CUPRAC (mg TE $\left.(\mathrm{g} \text { d.e. })^{-1}\right)$ & $111.14 \pm 1.39^{\mathrm{b}}$ & $165.53 \pm 6.08^{\mathrm{a}}$ \\
\hline
\end{tabular}

*Values followed by different letters in the same row are significantly different at $P<0.05$, according to the $t$-test. 
Table 2. Phenolic acid and flavonoid content $\left(\mathrm{mg} \mathrm{g}^{-1}\right)$ of untreated and treated lemon by-products. Results are expressed as mean \pm standard deviation $(n=5)$.

\begin{tabular}{ccccccc}
\hline & \multicolumn{3}{c}{ Phenolic acids } & \multicolumn{3}{c}{ Flavonoids } \\
\hline & Caffeic acid & $p$-Coumaric acid & Sinapic acid & Neohesperidin & Hesperidin & Rutin \\
\hline UB & $0.13 \pm 0.02^{\mathrm{b}^{*}}$ & $0.19 \pm 0.01^{\mathrm{b}}$ & $1.21 \pm 0.02^{\mathrm{b}}$ & $0.28 \pm 0.01^{\mathrm{b}}$ & $23.79 \pm 0.31^{\mathrm{b}}$ & $8.54 \pm 0.21^{\mathrm{b}}$ \\
TB & $0.53 \pm 0.05^{\mathrm{a}}$ & $0.66 \pm 0.06^{\mathrm{a}}$ & $2.17 \pm 0.11^{\mathrm{a}}$ & $1.91 \pm 0.04^{\mathrm{a}}$ & $27.10 \pm 0.33^{\mathrm{a}}$ & $12.25 \pm 0.46^{\mathrm{a}}$ \\
\hline
\end{tabular}

*Values followed by different letters in the same column are significantly different at $P<0.05$, according to the $t$-test. UB: Untreated by-product

TB: Treated by-product 


\section{Figures}

Fig. 1. Effect of two aqueous extracts obtained from the microwave treated and untreated lemon by-product on diameter growth (a), and per cent growth inhibition (b). Bars with different letters are statistically different at $P<0.05$ using the Duncan's post hoc multiple comparison test.

Fig. 2. Scanning electron micrographs of $A$. alternata hyphae. (a) Hyphae of untreated fungus (control); (b) Hyphae of fungus grown on $1 / 4$ PDA incorporated with extract (14 $\mathrm{mg} \mathrm{ml}^{-1}$ ) obtained from untreated lemon by-product; (c) Hyphae of fungus grown on 1/4 PDA incorporated with extract $\left(14 \mathrm{mg} \mathrm{ml}^{-1}\right)$ obtained from microwave treated lemon byproduct.

Fig. 3. Effect of two aqueous extracts obtained from the microwave treated and untreated lemon by-product on A. alternata spore germination. Bars with different letters are statistically different at $P<0.05$ using the Duncan's post hoc multiple comparison test.

\section{Supplementary material}

Fig. S1. Hyphal morphology of A. alternata 